\title{
Steroidogenic enzyme profile in an androgen-secreting adrenocortical oncocytoma associated with hirsustism
}

Milène Tetsi Nomigni ${ }^{1,2}$, Sophie Ouzounian ${ }^{3}$, Alice Benoit ${ }^{4}$, Jacqueline Vadrot ${ }^{5}$, Frédérique Tissier ${ }^{6}$, Sylvie Renouf ${ }^{1,2}$, Hervé Lefebvre ${ }^{1,2,7}$, Sophie Christin-Maitre ${ }^{3,8}$ and Estelle Louiset ${ }^{1,2}$

${ }^{1}$ INSERM, U982, Laboratory of Neuronal and Neuroendocrine Differentiation and Communication, Institute for Research and Innovation in Biomedicine, Mont-Saint-Aignan, France

${ }^{2}$ University of Rouen, Mont-Saint-Aignan, France

${ }^{3}$ Department of Endocrinology, Hôpital Saint-Antoine, Assistance Publique-Hôpitaux de Paris, Paris, France Departments of ${ }^{4}$ Endocrinology, Diabetes and Metabolic Diseases and ${ }^{5}$ Pathology, Hôpital Sud Francilien, Corbeil-Essonnes, France

${ }^{6}$ Department of Pathology, Assistance Publique des Hôpitaux de Paris, Hôpital Pitié Salpétrière, Pierre-et-Marie Curie University, Paris, France

${ }^{7}$ Department of Endocrinology, Diabetes and Metabolic Diseases, Rouen University Hospital, 76000 Rouen, France

${ }^{8}$ INSERM, U933, Paris, France

Correspondence

should be addressed

to H Lefebvre

Email

herve.lefebvre@chu-rouen.fr

The journal apologises for an error in the above paper, which appeared in volume 4 part 2, pages 117-127. The error relates to the incorrect spelling of 'hirsutism' in the title on page 117.

The correct title should read 'Steroidogenic enzyme profile in an androgen-secreting adrenocortical oncocytoma associated with hirsutism'.

http://www.endocrineconnections.org DOI: 10.1530/EC-15-0014e
(C) 2015 The authors Published by Bioscientifica Ltd

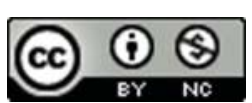

This work is licensed under a Creative Commons Attribution-NonCommercial 4.0 International License. 